\title{
Development Status and Prospects of Big Data Marketing
}

\author{
Jianying Yong \\ Yinchuan University of Energy, Yinchuan, Ningxia, 750105
}

Keywords: big data; marketing strategy; prospects and status

\begin{abstract}
With the acceleration of globalization of the Internet, the application of cloud computing, and the intensification of market competition, the combination of big data technology and marketing science has become a general trend. Big data brings an unprecedented new world to traditional marketing, and it also brings about new marketing ethics problems in traditional marketing. How to encourage the company use the opportunities brought by the era of big data, and make its marketing behavior ethical, is an important issue that should be paid attention to in all fields.
\end{abstract}

\section{Introduction}

With the development of cloud computing technology, the Internet, the Internet of Things, and the processing of real-time data streams, the era of big data has come. Enterprises and society will face a change. Companies that can use big data in a timely manner will undoubtedly have an important competitive advantage for sustainable development. The big data formed by countless individual data contains huge commercial information. Marketers can improve the product by analyzing big data and carry out accurate promotion activities. This can also increase marketing efficiency and return on investment while also saving corporate resources. It is precisely because of the enormous value of large amounts of individual data that is increasingly prominent, which makes individual data more active than before in collecting, processing, and trading activities. Various types of innovation emerge in an endless stream. Companies use the big data in the marketing field for their own benefit. However, personal data privacy is at risk of leaking at any time. In recent years, some companies even appear distorted and short-sighted in the use of big data. Personal data privacy breaches often occur. People's online behavior is exposed in the spotlight of big data. Personal space is harassed by spam and emails. These problems directly harm society and consumers, causing chaos in the use of big data systems, and at the same time, they also shake the credit system of the network and even the entire society. Ultimately, they will also harm the interests of enterprises.

\section{Big Data Marketing Paradigm Transformation}

From media guidance to user orientation In the early 21st century, the era of mass media marketing based on the eyeball economy, companies were the implementers and beneficiaries of brand promotion, and in order to reach more consumers with their promotional activities, they needed attention. Higher websites, television stations or paper media are placed on advertising in order to increase marketing efficiency. However, this type of mass media-based marketing promotion method has a high reach rate and a wide range of radiation, but it cannot accurately grasp the audience's movement and control its subsequent impact. Therefore, the transition from media-oriented to user-oriented marketing model is imminent. The custom-tailored follow-up marketing method based on the client gradually replaced the traditional unified one-time media placement and became the basis and predecessor of big data marketing.

Traditional data marketing is based on demographic data from market research and subjective information of other users (including lifestyle, value orientation, etc.) to estimate the needs of consumers, the possibility of purchase, and the corresponding purchasing power. Consumers, establishing target markets and further positioning product marketing models. However, due to the 
limitations of consumers' subjective judgments, various research indicators and information data obtained by the company may mislead relevant marketers to make deviations or even make wrong decisions. Therefore, the user's subjective information data can no longer meet the needs of corporate marketing. On the contrary, through the actual observation of enterprises, the user's objective behavioral database that can reflect users' needs and other consumption data in an all-round, multi-angle, accurate and authentic manner has become an important research basis for enterprise marketing as the information mining technology becomes more and more perfect.

\section{Development Status of Big Data Marketing}

One of the types of big data currently used by enterprises is self-owned data, which is a type of data developed and mined by enterprises based on their own network platform. In China, the development process of self-owned data is still not perfect. Currently, self-owned data platforms that operate better are mainly founded in Europe and the United States. U.S. streaming media giant Netflix conducted big data analysis of the online behavior of its 30 million subscribers, creating and predicting the sale of "House of Cards." Nike, a sports brand, has collected all the user's running information with his online sports community and has thus mastered the database of the best running routes in major cities. The Target supermarket inferred the consumer's shopping tendency based on the member's consumption records, and then recommended a series of products that meet the demand by sending a shopping manual and finally succeeded in marketing. These enterprise-owned data platforms based on different forms of existence consistently play the role of information providers in the field of data collection. However, they use their data to make their own contributions to the big data marketing of enterprises at different levels. .

In addition to the self-built big data collection platform, the most important channel for enterprises to obtain data now is through cooperation with third-party platforms such as portal websites, e-commerce websites, search engines, social networking sites, and mobile payments. The WeChat platform cooperation agreement between Jingdong and Tencent not only made up for the weak link of JD.com, but also introduced a considerable amount of customer traffic. In this era of mobile Internet social networking, the huge data contained in massive user resources is large. Data precision marketing offers possibilities. Meiyijia, as a small and medium-sized enterprise that is exploring the development from the offline to the online, is not only the magic weapon for opening the online market, but also a key step for the accurate marketing of data. .

Customize the product based on the user's needs. Consumers' intentional or unintentional information data left as a reflection of their potential needs is a powerful basis for companies to customize and improve their products. ZARA's internal global information network will periodically collect and pass on customer opinions and suggestions collected from each branch to the designers of the headquarters. After the decision is made by the headquarters, the new design will be immediately transmitted to the production line until the data is finally realized. The whole process of making clothes. Taking advantage of this, ZARA, as a company with a strategy of standardization and localization, has also analyzed the regional colors in various regions and has made the market segment that is closest to the needs of customers while maintaining the overall European and American style of its apparel. . Similarly, in ZARA's online store, consumer opinions are also used as a market research big data to participate in R\&D and production of corporate products, and the resulting forward-looking views and fashion trends have also made 'Fast Fashion' a brand of ZARA.

\section{Future Development Trends of Big Data Marketing}

With the development and reform of information technology, the dispersion of consumers and the fragmentation of user databases caused by single media can no longer meet the demand for data quantity and diversity. In the all-media era, the media's cross-border integration enabled dispersed users to gather and concentrate, and the inter-media data connectivity enabled fragmented consumer databases to be coordinated and integrated. Although we are still in the exploratory phase from the 
data fragmentation to the era of data integration, with the development of technology in the future, the multi-channel cross-media, cross-platform, and cross-terminal communication will fully reorganize information. On the basis of diversified media networks, the effective integration of consumer objective data and subjective information to form a complete user database will become an inevitable trend in the future development of big data marketing. Big data marketing based on a complete database will present more accurate and effective user demand mining, and the integration of diverse information also enables the data to more fully reflect the consumer's hobbies, habits, personality, and even potential demand for commercial value. Mobile phones, televisions, and the Internet serve as channels for users to receive information and can objectively record the user's demographic and behavioral data. The co-creative communication platforms such as online communities and social platforms can be used as channels for user output data to create topics. , Guide discussions, so that users really become producers and producers of content, actively participate in information feedback and real-time interactive sharing. In this way, through effective linkage among multiple media, realizing comprehensive and multi-angle feedback cooperation and integration of consumer information will be the key and foundation for all-media big data marketing.

Current data mining technologies and visualization technologies (such as cloud computing) have been able to store and analyze transactional processes, product usage, and human behavior in a real-time manner. However, with the development of science, the speed of data computing has been further improved and the data mining technology has also been more perfect. In-depth data analysis will not only make consumers' whereabouts more and more easy to grasp, but also the user's thinking will be more accurately dig at the same time. From the search for a product of consumer preference to the calculation of a specific element of its specific sentiment; the demand is being refined in the form of tiny elements, and more concretely displayed on the psychological level of the consumer. As a new technology, in-depth computing not only enables consumers to enter the age of big data, which is almost transparent and survives, but the new opportunities that arise along with it also enable the company's personalized marketing to develop in a more refined direction. At present, this technology has made customized product recommendations based on user preferences and habits more precise and accurate. However, in the future, if an enterprise truly wants to provide each terminal consumer with the products and services they want most, simply relying on personalized product recommendations can no longer satisfy consumers' increasingly 'demanding' consumer demands. On the contrary, providing customized product designs that fully meet customer requirements will become the mainstream of the data marketing community.

The characteristics of big data, such as its strong technology, large virtuality, and high flexibility, can lead to many unpredictable and uncontrollable operations. The law is only an external constraint. To solve the problem fundamentally, it must also rely on internal factors. It is necessary to form an ethical marketing concept within the enterprise that uses big data marketing, so that ethical marketing becomes a self-conscious behavior and self-discipline is used to fill in. Many management defects that are beyond the law. From another perspective, if marketers do not want the government to intervene too much in macroeconomic laws and policies to conduct big data marketing, companies must establish a protection mechanism for consumer privacy to ensure the safety of consumer privacy information and protect consumers. rights and interests. In this regard, because of the earlier development of the Internet in the United States, and the large-scale data collection technology is mature, the treatment of ethical issues in big data marketing is also representative. Between legal restrictions and industry self-regulation, the government prefers to use industry self-discipline to protect information security. This practice has also been supported by most enterprises, because companies do not want the government to interfere too much with its marketing activities, and are particularly afraid of government adoption. Over-bureaucratic systems and lengthy procedures to monitor and regulate their big data behavior reduce industry efficiency, and are more flexible through industry self-regulation. Essentially, self-discipline when dealing with ethical issues in big data marketing is the most cost-effective method. It can solve problems at the source and kill problems in the cradle. 


\section{Conclusion}

This article analyzes the status quo of the development of big data marketing and the challenges it faces at the current stage. Through the exploration of the future development trend of big data marketing, this paper further elaborates on the basis of data collaboration and depth in the context of cross-border media integration and deep data mining. The calculated personalized marketing will become the direction of future business development.

\section{References}

[1] Wang Zhongliang. Reengineering Marketing: Advertising Marketing Transformation in the Era of Big Data [J]. Sales and Management, 2012(1):12.

[2] Zhao Yihe. Marketing strategy of big data generations: fast, accurate, and stable [J]. Sound Screen World • Advertiser, 2012(1):46.

[3] Genggeng. Challenges of Opportunity in the Era of Big Data [J]. New Era of China, 2012(172):60- 61.

[4] Bjorn Brouhins, Lars Lack, Thomas Rams. Big Data Transformation [M]. Beijing: Mechanical Industry Press, 2014: 1- 15.

[5] Jia Lijun, Xu Xin. On the nature of "big data” and its marketing implications[J]. Nanjing Social Sciences, 2013(7):15- 21. 